\title{
A new project: a re-launch of strategy
}

Florin Mihălțan ${ }^{1,2, \dagger}$, Ruxandra Ulmeanu ${ }^{1,3}$, Beatrice Mahler ${ }^{1,2}$

${ }^{1}$ Marius Nasta Pneumoftiziology Institute, Bucharest, Romania

${ }^{2}$ Carol Davila University of Medicine and Pharmacy, Bucharest, Romania

${ }^{3}$ Faculty of Medicine, Oradea, Romania

The "Marius Nasta" Pneumoftiziology Institute, the National Program for the Prevention, Supervision and Control of Tuberculosis in Romania (PNPSCT) and the Romanian Society of Pneumology officially launched on November 20th, 2018, the E-DETECT TB program, the first active tuberculosis (TB) screening campaign in our country, made through a mobile medical unit with imaging and molecular diagnostic equipment.

E-DETECT TB is a wide-ranging project at the European level in countries such as Bulgaria, Italy, Great Britain, the Netherlands, Romania and Sweden with early diagnostics in Romania supported by the National Program for the Supervision and Fight against Tuberculosis (PNPSCT) and is coordinated by the "Marius Nasta" Pneumoftiziology Institute in order to ensure the early, active detection of TB patients. This part of the project was welcomed in the context that TB is a major public health problem in Romania, with the highest incidence of disease among all countries of the European Union (1).

Of course, if we make a short history of the problems faced by pneumologists in the years after 1989 in the country and in the Marius Nasta Pneumoftiziology Institute, we realize that a change in strategy was mandatory.

Actual issues with very high prevalence in vulnerable groups, that must be identified and treated could be avoided if immediately after 1989 revolution such donations, like the caravan were available. Vulnerable populations will be at the heart of the E-DETECT TB project, and active detection with these caravans will include detainees, homeless people, Roma, drug users and very poor populations with limited access to health care. Why should the strategy be reoriented?

Because in these categories, the incidence of TB is up to 7.5 times higher than the average (2) recorded in the population, per total. Examples are multiple:

- In the Roma population, according to the epidemiological surveillance data, the incidence of TB is approximately 2.5 times higher than in the general population (3).
- In 2017, 105 new and recurrent cases of TB were reported in the prison penitentiary, which is approximately 7.5 times higher than the general population (2).

The amplitude of the project will allow for the examination of about 20,000 people within E-DETECT TB with the possibility of extending up to 25,000 beneficiaries. The examinations will be carried out with the help of a mobile medical unit, equipped with imaging equipment and molecular diagnostics, by specialists from the Marius Nasta Pneumoftiziology Institute, with the support of PNPSCT.

The first step will be to complete a medical questionnaire at the entrance of the person, which will be examined in the mobile medical unit, and the registration of medical and sociodemographic data. Then, a chest X-ray will be performed, which will be transmitted via a telemedicine system to the Marius Nasta Pneumoftiziology Institute, where a pneumologist from the project will analyse the imaging result. Simultaneously, the result will be interpreted by a partner from the Netherlands - the KNCV Tuberculosis Foundation.

TB suspects identified after anamnesis and an abnormal chest X-ray, will give a sputum specimen for bacteriological investigation. The mobile medical unit is equipped with an advanced automated diagnostic system that identifies the Mycobacterium tuberculosis (MTB) DNA complex and the resistance to one of the antibiotics used in the treatment of TB. Patients diagnosed with TB will later enter in a full treatment and follow-up program (including interventions to increase adherence to treatment) in line with national recommendations on TB control. The total value of the project in our country was 970,449 euros, co-financed by the Ministry of Health, which allocated 612,069 euros.

Although data show that in our country every year about 1,000 people die from TB and about 16,000 people get sick of TB, most of them from the young and active population (1), the incidence in Romania in 2016 being five times the EU average (20\% of all cases reported in the EU being attributed to Romania, who has only $4 \%$ 
of the EU population (1)), the current efforts have managed to bring a substantial decrease in the burden of this disease.

Substantial support from authorities will allow the project integration and, at the Press Conference, Health Minister and National Institute representatives mentioned other measures endorsing the project, like: financial support for this sample population, anti-TB medication in resistant TB forms and concerns for multi- drug resistance MDR services.

\section{References}

1. INSP. Available from: http://insp.gov.ro/sites/cnepss/wp-content/ uploads/2018/03/analiza-de-situatie-tbc-2018-final.pdf.

2. PNPSCT - Departamentul de Evaluare-Monitorizare. 2018.

3. INSP - Departamentul de Supraveghere Epidemiologică. 2018. 